\title{
Editorial
}

\section{Is it Time to Study Leukodystrophies?}

Oligodendrocytes and astrocytes have been penalized and maintained in shadows by the Neuron Doctrine ${ }^{[1]}$ that considers neurons and synaptic contacts as the only center of the nervous system and assigns to glia a simple supporting role. Even today, the lack of a fully recognized background on oligodendrocytes' role and response in physiological conditions makes it harder to understand their mechanistically disturbances that are associated with major diseases of the nervous system.

Specifically, it is the case of leukodystrophies, a group of rare, progressive, metabolic, genetic heritable myelin disorders affecting primarily oligodendrocytes in the central nervous system with or without peripheral nervous system myelin involvement. Each type of leukodystrophy is caused by a specific gene mutation that turns into abnormal development or destruction of the white matter, leading to a range of neurological problems. Unfortunately, the symptoms' appearance is mutation associated, and the many types of clinical manifestations often delay the specific leukodystrophy identification by complication of differential diagnosis. Moreover, to establish the specific leukodystrophy, the medical history and the detailed family history need to be associated with physical and neurologic examination, review of brain magnetic resonance imaging findings, molecular genetic testing, and enzyme activity screening.

Under these premises and considering that the rare leukodystrophies are often less studied than neuron disorders with a higher social and "academic" impact, the epidemiologic data on the frequency of leukodystrophies overall are limited. The relative frequency of each specific leukodystrophy is not established or, in my opinion, it is generally underestimated, due to the heterogeneity and complexity both of the disorder manifestations and of the genetic profile. This latter is often complicated by unknown polymorphisms that are usually misinformative for the diagnosis. ${ }^{[2-3]}$ This situation is common all over the world, no matter the developmental or economic status. It is much more severe in regions where the specialized clinics are missing, the economic resources are limited, and the research development is reduced.

By taking in mind this state of art, the manuscript "Clinical and Genetic characteristics of Leukodystrophies in Africa" ${ }^{\text {[4] }}$ acquires a fashionable appeal and an intense social implication. In fact, the African populations have been selected for its genomic heterogeneity linked to the high burden of neurological disorders; the currently developed research in leukodystrophies in Africa has been reviewed. The search on electronic databases identified Metachromatic leukodystrophy, Krabbe disease, Canavan disease, X-linked adrenoleukodystrophy, and Megalencephalic leukoencephalopathy, as the most described leukodystrophies in Africa. Thus, the paper has been developed as a "mini registry" of each disease. The description of current knowledge is associated to the evaluation of genotype and epidemiologic data from specific African areas.

The main topic is perfectly pointed out: the hope of increasing the awareness of researchers, clinicians, and global organizations for participating in the research of leukodystrophies, to obtain epidemiological data, also.

I agree: the identification of novel mutation and the description of the leukodystrophies physiology (at molecular, cellular, tissue, and organism level) need the synergic action of researchers and clinicians, but I add that also the politics and the funding association should be more sensible to the question. For example, the financial support for the institution of a worldwide registry and biobank of leukodystrophies could improve the basic understanding, support the possibility of prospective analysis, and aid the evaluation of genotype-phenotype correlation.

Moreover, the glia and specifically, the oligodendrocytes should acquire its own identity among the neuroscientists, and the academic committee for researchers' evaluation should be less influenced by the Neuron Doctrine to apply a multidisciplinary approach that represents the only way to significantly shed the light on the leukodystrophies.

Adriana Carol Eleonora Graziano

Department of Biomedical and Biotechnological Sciences, University of Catania, Catania, Italy

Address for correspondence: Dr. Adriana Carol Eleonora Graziano,

Department of Biomedical and Biotechnological Sciences, University of Catania, Via S. Sofia, 97, 95123 Catania, Italy. E-mail: acegraz@unict.it

\section{REFERENCES}

1. von Waldeyer-Hartz HW. Über einige neuere forschungen im gebiete der anatomie des central nerven systems. Dtsch Med Wochenschr 1891;17:1213-8, 1244-1246, 1287-1289, 1331-1332, 1350-1356.

2. Szymanska K, Lugowska A, Laure-Kamionowska M, Bekiesinska-Figatowska M, Gieruszczak-Bialek D, Musielak M, et al. Diagnostic difficulties in Krabbe disease: A report of two 
cases and review of literature. Folia Neuropathol 2012;50:346-56.

3. Graziano AC, Cardile V. Genetic test and gene therapy for Krabbe disease: An update. Gene Technol 2015;4:118.

4. Amin M, Elsayed L, Ahmed AE. Clinical and genetic characteristics of leukodystrophies in Africa. J Neurosci Rural Pract 2017;8:S89-S93.

This is an open access article distributed under the terms of the Creative Commons Attribution-NonCommercial-ShareAlike 3.0 License, which allows others to remix, tweak, and build upon the work non-commercially, as long as the author is credited and the new creations are licensed under the identical terms.

\begin{tabular}{|c|c|}
\hline \multicolumn{2}{|c|}{ Access this article online } \\
\hline $\begin{array}{c}\text { Quick Response Code: } \\
\square[\end{array}$ & $\begin{array}{l}\text { Website: } \\
\text { www.ruralneuropractice.com }\end{array}$ \\
\hline 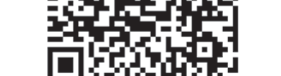 & $\begin{array}{l}\text { DOI: } \\
\text { 10.4103/jnrp.jnrp_146_17 }\end{array}$ \\
\hline
\end{tabular}

How to cite this article: Graziano AC. Is it time to study leukodystrophies? J Neurosci Rural Pract 2017;8:S1-2. 